\title{
A Mutation in the Lipoprotein Lipase Gene Is the Molecular Basis of Chylomicronemia in a Colony of Domestic Cats
}

\author{
David G. Ginzinger, ${ }^{\star}$ M.E. Suzanne Lewis, ${ }^{\star}$ Yuanhong Ma, ${ }^{\ddagger}$ Boyd R. Jones, ${ }^{\S}$ Guoqing Liu, ${ }^{\star}$ Sarah D. Jones, ${ }^{\star}$ \\ and Michael R. Hayden* \\ Departments of $*$ Medical Genetics and ${ }^{\ddagger}$ Medicine, University of British Columbia, Vancouver, British Columbia V6T 1Z4, Canada; \\ and ${ }^{\S}$ Department of Veterinary Clinical Sciences, Massey University, Private Bag 11222, Palmerston North, New Zealand
}

\begin{abstract}
Members of a domestic cat colony with chylomicronemia share many phenotypic features with human lipoprotein lipase (LPL) deficiency. Biochemical analysis reveals that these cats do have defective LPL catalytic activity and have a clinical phenotype very similar to human LPL deficiency. To determine the molecular basis underlying this biochemical phenotype, we have cloned the normal and affected cat LPL cDNAs and shown that the affected cat has a nucleotide change resulting in a substitution of arginine for glycine at residue 412 in exon 8 . In vitro mutagenesis and expression studies, in addition to segregation analysis, have shown that this DNA change is the cause of LPL deficiency in this cat colony. Reduced body mass, growth rates, and increased stillbirth rates are observed in cats homozygous for this mutation. These findings show that this LPL deficient cat can serve as an animal model of human LPL deficiency and will be useful for in vivo investigation of the relationship between triglyceride rich lipoproteins and atherogenic risk and for the assessment of new approaches for treatment of LPL deficiency, including gene therapy. (J. Clin. Invest. 1996. 97:1257-1266.) Key words: lipoprotein lipase • animal model $\cdot$ chylomicronemia $\cdot$ cat $\cdot$ molecular genetics
\end{abstract}

\section{Introduction}

Lipoprotein lipase (LPL; triacylglycero-protein acylhydrolase, EC 3.1.1.34) ${ }^{1}$ is a crucial enzyme in the regulation of lipoprotein and lipid metabolism. LPL-mediated hydrolysis of triglycerides from circulating chylomicrons and VLDL facilitates the production and cellular uptake of fatty acids for energy metabolism, primarily in muscle and for storage in adipose tissues (1). The lipoprotein remnants derived from VLDL and chylomicrons are important contributors to the formation of HDL (2) and as a result, levels of HDL cholesterol are directly correlated with plasma LPL activity in humans (3).

Address correspondence to Dr. Michael R. Hayden, Department of Medical Genetics, University of British Columbia, 416-2125 East Mall, Vancouver, British Columbia V6T 1Z4, Canada. Phone: 604822-9240; FAX: 604-822-9238; E-mail: mrh@ulam.generes.ca

Received for publication 11 October 1995 and accepted in revised form 6 December 1995.

1. Abbreviation used in this paper: LPL, lipoprotein lipase.

J. Clin. Invest.

(C) The American Society for Clinical Investigation, Inc. 0021-9738/96/03/1257/10 \$2.00

Volume 97, Number 5, March 1996, 1257-1266
The cellular origin of LPL in the circulation remains uncertain. Although LPL is produced mainly by parenchymal cells such as adipocytes, muscle cells and macrophages, its site of primary function is the luminal surface of the vascular endothelium $(4,5)$. There it is bound by the heparin-sulfate side chains of membrane glycoproteins. LPL is displaced to the plasma after intravenous injection of heparin, which allows assessment of its in vivo activity. Active LPL is a noncovalently linked homodimer of two 50-kD glycoprotein chains and requires the presence and binding of apolipoprotein CII $(5,6)$.

Complete LPL deficiency is a serious autosomal recessive disorder which usually manifests in childhood with acute pancreatitis, chylomicronemia, failure to thrive, eruptive xanthomata, and lipemia retinalis $(1,7)$. Members of a naturally occurring, inbred colony of cats presented with chylomicronemia (8), which raised the possibility that these cats may be suffering from LPL deficiency. Biochemical analysis indeed revealed that these cats do have a deficiency of plasma LPL catalytic activity, yet possess normal function of the LPL cofactor, apo CII (9). However, the molecular basis for these biochemical features remained unresolved.

We have now performed molecular studies and identified a causative mutation in the cat $L P L$ gene. We report here the cloning of the cat $L P L$ cDNA and the identification of a G to A transition at nucleotide 1234 in exon 8 resulting in a substitution of arginine for glycine at residue 412. Further assessment of the significance of this amino acid substitution by both site-directed in vitro mutagenesis and segregation analysis of this mutation with the affected cat phenotype, confirms that Gly412Arg mutation is the cause of LPL deficiency in this feline colony.

There is increasing evidence of the relationship between triglyceride-rich lipoproteins and progression of coronary artery disease. However, the role of increased triglyceride levels associated with LPL deficiency on the development of atherosclerosis is yet to be assessed in an in vivo experimental system. The availability of a proven animal model of human LPL deficiency will afford a unique opportunity to assess, in vivo, the biochemical features associated with LPL deficiency and to directly assess the relationship between triglyceride rich lipoproteins and atherosclerosis.

\section{Methods}

Animals. The animals in this study are members of a colony of domestic cats (8) that have been maintained at the animal care unit at University of British Columbia (UBC). These cats have been fed a standard commercial diet, either Hill's prescription diet - Feline $\mathrm{r} / \mathrm{d}$ or Whiskas with tuna, both of which have no more than $12 \%$ fat. All cats were allowed to feed ad lib. on both the wet and dry foods.

Plasma lipid analysis. Blood was obtained through the jugular 
vein of sedated animals $(0.1 \mathrm{ml}$ Ketamine $/ \mathrm{kg}$ body wt $)$ anticoagulated with EDTA and spun at 2,000 rpm for $15 \mathrm{~min}$ in a standard table-top centrifuge. Plasma was removed for lipid determinations. Total cholesterol and total triglycerides were determined enzymatically using commercially available kits (Boehringer Mannheim, Mannheim, Germany). HDL cholesterol levels were determined after precipitation of other lipoproteins with heparin manganese. LDL cholesterol levels were calculated according to the following formula: Total cholesterol minus (HDL cholesterol + Triglycerides/2.2). FPLC analysis was conducted with an LCC 501 plus controller and model 500 pump using a Sephadex 6 column (Pharmacia LKB Biotechnology Inc., Piscataway, $\mathrm{NJ}$ ), using standard methods (10).

LPL enzymatic activity and immunoreactive mass. A blood sample was taken before, and $10 \mathrm{~min}$ after the administration of sodium heparin $(100 \mathrm{U} / \mathrm{kg})$ for determination of LPL mass and activity. LPL protein mass and lipolytic activity was determined as previously described $(11,12)$. In brief, LPL activity was calculated as the fraction of total lipolytic activity that can be blocked with the addition of an $\mathrm{mAb}(5 \mathrm{D} 2)$ that binds to the LPL protein rendering it inactive or by the addition of $1 \mathrm{M} \mathrm{NaCl}$ which preferentially inactivates LPL. The remaining lipolytic activity is attributed to hepatic lipase. LPL protein mass was determined by ELISA using the mAbs 5F9 and 5D2 as previously described $(11,13)$.

Northern analysis. Total RNA was isolated from 12 tissue types and prepared using the standard acid-guanidium isothiocyanate method of Chomczynski and Sacchi (14). Approximately $10 \mu \mathrm{g}$ of total RNA from each tissue was loaded per lane on a $1 \%$ formaldehyde gel and run overnight at $30 \mathrm{~V}$. The RNA ladder was cut from the gel, stained with ethidium bromide and photographed to help estimate the size of the transcripts. The gels were soaked in DEP-treated water for $\sim 2 \mathrm{~h}$ before blotting overnight. The blots were baked at $80^{\circ} \mathrm{C}$ for $2 \mathrm{~h}$ then prehybridized in Church buffer with 1\% BSA added for $2 \mathrm{~h}$. The Northern filters were hybridized with a random primer labeled (15) normal cat $L P L$ cDNA overnight at $60^{\circ} \mathrm{C}$. The filters were washed in $2 \times$ SSC and $0.1 \%$ SDS for $30 \mathrm{~min}$ at room temperature then washed two times in $0.5 \mathrm{x}$ SSC plus $0.1 \%$ SDS at $60^{\circ} \mathrm{C}$ for $30 \mathrm{~min}$ each. Filters were then exposed to XAR5 autoradiographic film (Eastman Kodak Co., Rochester, NY) for $1-3 \mathrm{~d}$ at $-70^{\circ} \mathrm{C}$.

Cloning and sequencing of the normal cat LPL gene. A cDNA library was constructed from RNA isolated from adipose tissue of a normal cat by the method of Chomczynski and Sacchi (14). Poly A+ RNA was purified by oligo dT column chromatography. First and second strand cDNA synthesis was performed using standard methods (16). Lambda arms were ligated to double-stranded cDNA and then ligated into the lambda gt11 cloning vector. Packaging and screening of library were also performed using standard methods (16). Several positive plaques were purified and subcloned into the Bluescript sk $+/-$ plasmid (Stratagene Inc., La Jolla, CA) and used to transform DH5 competent cells (GIBCO BRL, Gaithersburg, MD). DNA from positive colonies was purified by a standard alkaline lysis mini-prep method (16) which was suitable for sequencing using the dideoxy chain termination method (17) using reagents from USB Biologicals (Cleveland, $\mathrm{OH}$ ) using the following primers: N17 (nt 1289-1310) (5'-GGTCAGACTG-GTGGAGCAGCCC-3') N18 (nt 1404-1428) (5'-CACAAATACCGCAGGTGCCTTTCC-3') 1171 (nt 1126-1147) (5'-CTTT-GTAAGGCATCTGAGACCG-3') N11 (nt 781-792) (5'-AAGTCCTCTCTCTCGCAATCAC-3') N10 (nt 607-630) (5'-GCGACTTGGAGCTTCTGCATATTC-3') N23 (nt 583-603) (5'-CTAGATCCAGCTGGACCTAAC-3') M56 (nt 166183) (5'-CTAAGGACCCCTGAAGACACAGCT-3').

Initial screening of the normal feline cDNA library identified a partial cDNA clone for the feline $L P L$ gene using a human LPL cDNA clone as a probe (18). This clone contained an insert of about $900 \mathrm{bp}$, which showed significant similarity to the human $L P L$ gene. A full length $L P L$ clone was not found in this library. We therefore used a RACE method (19) to obtain sequence in the $5^{\prime}$ region of the feline $L P L$ gene. The RACE-PCR products obtained were blunt end ligated into the pBluescript $\mathrm{k} / \mathrm{s}$ vector (Stratagene Inc.) and se- quenced by the dideoxy chain termination method (17) (USB Biologicals).

In addition, we designed a set of PCR primers based on a high degree of sequence similarity between the promoter region of mouse and human LPL genes (20). The $5^{\prime}$ end primer (5'-CCACTTATGATTTTATAGCCAATAGG- $3^{\prime}$ ) was designed at the position -83 to -57 in the mouse $L P L$ gene (which is completely conserved in the human gene). A second primer N24(5'-CCGTGACAGCCAGTCCACCAC-3') was synthesized complimentary to a region $550 \mathrm{bp}$ downstream of the $5^{\prime} \mathrm{LPL}$ primer. A third primer N55(5'-AAGTCCTCTCTCTGCAA-TCAC-3') was used to prime a reverse transcribed cDNA copy from total RNA isolated from adipose tissue of a normal cat and mouse. These cDNAs were amplified using the $5^{\prime} \mathrm{LPL}$ primer and primer $\mathrm{N} 24$ with the following conditions; $1.5 \mathrm{mM} \mathrm{Mg} \mathrm{Cl}$, 75 mmol dNTP's, 50 pmol primer 5' LPL and N24, 1\% formamide in $100 \mu \mathrm{l}$ reaction. Cycle parameters used for a thermocycler (480; Perkin Elmer Cetus Instruments, Emeryville, CA) were: 35 cycles at $94^{\circ} \mathrm{C}$ for $1 \mathrm{~min}, 67^{\circ} \mathrm{C}$ for $1 \mathrm{~min}, 72^{\circ} \mathrm{C}$ for $2 \mathrm{~min}$, with a final extension of $10 \mathrm{~min}$ at $72^{\circ} \mathrm{C}$. The PCR products were sequenced using a thermocycle sequence kit (New England Biolabs Inc., Beverly, MA).

Cloning and sequencing of the affected cat LPL gene. In a manner similar to that described above, reverse transcriptase (RT)-PCR was used to generate a copy of the affected cat $L P L$ gene from skeletal muscle RNA. A primer $3^{\prime} \mathrm{UTR}\left(5^{\prime}\right.$-CTGTTCTTCCTTCT-GTAGATTTGCCC-3') specific to the $3^{\prime}$ end of the feline LPL gene was used to generate a reverse transcribed cDNA copy. This single strand copy was used as the template for PCR amplification with gene-specific primers that span the coding region of the normal cat $L P L$ gene. These PCR products were then used to generate single strand sequencing template for asymmetric sequencing in which one primer is limiting (1/100 the concentration of the other primer) resulting in a linear amplification of a single strand product suitable as a sequencing template. Using asymmetric PCR to generate sequencing template, the normal and affected cat $L P L$ cDNAs were sequenced on both strands, in duplicate, with the dideoxy chain termination method (17) using reagents from USB Biologicals. The sequencing of both the normal and affected cat LPL cDNAs has since been confirmed using automated sequencing techniques (ABI, Foster City, CA).

In vitro mutagenesis and Cos-1 cell transfections. The human $L P L$ gene was ligated, in the sense orientation, into the phagemid vector CDM8. The ligated recombinant DNA was transfected into MC1061/ p3. Purified CDM8-LPL DNA was then transfected into a dut(-) ung $(-)$ host $\left(\mathrm{BW} 313 / \mathrm{p} 3 / \mathrm{F}^{\prime}\right)$ to generate a uracil-containing clone (21). In vitro mutagenesis and transfection of COS-1 cells was performed as described previously (22). The cell-free medium was used to measure LPL activity.

The normal and affected (Gly412Arg homozygote) cat $L P L \mathrm{cDNAs}$ were obtained using standard RT-PCR techniques (23). These products were sequenced twice on both strands to ensure that there were no Taq errors that would result in a defective protein. Once they were confirmed, they were cloned into the pcDNA3 expression vector (InVitrogen Corp., San Diego, CA). These constructs were then used to transfect Cos-1 cells as described previously (22). The cell-free medium was used to measure LPL activity.

Assay for the 412 mutation and segregation analysis in the cat colony. The 412 mutation does not alter any known restriction endonuclease recognition sites. However, based on the similarity of organization between the human and mouse $L P L$ genes (20), the nucleotide substitution at codon 412 is located 16 bases from the predicted $3^{\prime}$ end of exon 8. To develop a PCR-based screening protocol, sequence from intron 8 of the cat $L P L$ gene was required. This was facilitated by PCR amplification using primers N20(5'-TGGAAGAGC-GATTCATACTTCAGCTGG-3') and N22(5'-CTGAACAGTACCGTAAAGTGTTTATGG-3') flanking exon 8 . The resulting PCR product was directly sequenced by thermocycle sequencing techniques (New England Biolabs). Once the intronic sequence was determined, a primer I8(5'-ACCTGAACGTTGAAGGCTCCAAGAGTACCC$\left.3^{\prime}\right)$ was developed in the intron that, in conjunction with a mismatch 
primer MM-SB(5'-GGTTTACTATTGAGAAGA-TCAGAGTAAAACCA-3') in the exon, produced an amplification product amenable to separation on a standard agarose gel after digestion at the restriction site introduced in the mismatch primer. A fragment of 135 bp was selected to facilitate the resolution of the digestion products upon electrophoresis in a 3\% agarose gel. The mismatch introduced in primer MM-SB creates a new restriction endonuclease recognition site (BstNI) only on the normal allele. Amplification conditions are: $1.5 \mathrm{mM} \mathrm{Mg} \mathrm{Cl}, 75 \mathrm{mmol}$ dNTP's, 50 pmol primers MM-SB and I8-2, $0.5 \mathrm{U}$ Taq. Polymerase in $100 \mu \mathrm{l}$ reaction volume. Cycle parameters used for a Perkin Elmer Model 480 thermocycler were: 35 cycles at $94^{\circ} \mathrm{C}$ for $1 \mathrm{~min}, 67^{\circ} \mathrm{C}$ for $1 \mathrm{~min}, 72^{\circ} \mathrm{C}$ for $45 \mathrm{~s}$. After PCR amplification of genomic DNA from members of the cat colony, the amplification products are digested with the BstNI restriction endonuclease ac- cording to manufacturer's recommendations (New England Biolabs). The digestion of these products results in the cleavage of $30 \mathrm{bp}$ of the 135-bp product only on the normal allele which is then resolved on a $3.0 \%$ agarose gel. This mismatch analysis provides a simple method to determine the genotype of each animal in the colony.

Growth curves and stillborn rates. All kittens were maintained on a similar diet from the weaning period through adulthood. Kittens homozygous for this mutation were cross-fostered at day 2 by a normal queen, due to the homozygous queen's reduced ability to lactate. Each kitten was weighed daily, and weights were averaged for each genotype and plotted as a function of time.

Stillbirth rates were tabulated from the entire breeding colony of LPL-deficient cats at UBC and in New Zealand as well as those bred for other investigators at UBC. After the queening of a new litter the




number of live offspring and the number of dead offspring were recorded. Affected queens are homozygous for the Gly412Arg mutation. The stillbirth rate is calculated as the number of live offspring over the number stillborn and is expressed as a percentage.

\section{Results}

Isolation of the cat LPL $c D N A$. A normal feline adipose cDNA library was screened using a human $L P L$ cDNA clone as a probe (18). Positive clones were identified and the largest clone contained an insert of $\sim 900 \mathrm{bp}$, which is $\sim 500 \mathrm{bp}$ shorter than the full length human cDNA clone. To obtain the full length sequence, a 5' RACE (19) procedure was performed which provided all but 125 nucleotides from the predicted $5^{\prime}$ end of the normal cat gene. To derive sequence from the $5^{\prime}$ end, a PCR primer (5'LPL) was developed based on the high degree of sequence homology between the promoter region of mouse and human $L P L$ clones (20). The antisense oligonucleotide primer (N24) was based on the sequence of the normal cat $L P L \mathrm{cDNA}$. Together they were used to generate a 550-bp product from reverse transcribed adipose tissue RNA, from the mouse and cat, which revealed a product of the expected size and hybridized to the human $L P L$ gene. The complete coding region plus $\sim 125$ bp of $5^{\prime}$ UTR was generated for the normal cat $L P L$ cDNA. Amplification of a transcript $5^{\prime}$ to the primary transcription initiation start site which has sequence similarity to the mouse and human $L P L$ genes and overlaps with the cat $L P L$ gene suggested either that we had amplified an alternate transcript (Northern analysis indicates a larger transcript is present) or that this is the result of amplification of cat genomic DNA. Either way, however, because of the sequence similarity with published $L P L$ genes and the overlap with the previously sequenced cat $L P L$ gene, this strongly suggested that this is indeed the correct sequence of the $5^{\prime}$ end of the feline $L P L$ gene.

Sequence analysis. The cat cDNA sequence contains 1,512 nucleotides and includes a predicted open reading frame of 451 amino acid residues (Fig. 1). The sequence includes 34 nucleotides of the $3^{\prime}$ untranslated region and $125 \mathrm{bp}$ of $5^{\prime}$ UTR. A three amino acid insertion at the beginning of the predicted mature peptide of the cat cDNA is present, similar to bovine $L P L$ (24) but not observed in the human $L P L$ cDNA (18).

Nucleotide and amino acid sequence comparison between the human and cat $L P L$ cDNAs reveals nucleotide and predicted amino acid similarity of 90 and $94.5 \%$, respectively. Comparison of the predicted amino acid sequence of $L P L$


Figure 2. Nucleotide sequence of a region of exon 8 of the normal and affected cat cDNAs showing a G to A transition at position 1234 resulting in a substitution of arginine for glycine at residue 412 in the $\mathrm{COOH}$ terminus of the LPL protein.

from mouse (25), rat (26), bovine (24), and guinea pig (27) reveals $\sim 85 \%$ identity to human $L P L$ cDNA. Chicken $L P L$ contains 15-17 additional COOH-terminal residues and 73$77 \%$ sequence identity with mammalian LPLs, (74\% with human) (28).

Sequence comparison of the normal and affected cat cDNAs identified a single DNA change ( $G$ to A transition) at position 1234 of the cat LPL gene which corresponds to amino acid residue 412 in the cat (409 in the human $L P L$ cDNA) and results in a substitution of arginine for glycine (Fig. 2). The identification of the Gly412Arg substitution was the only difference identified between the normal and affected cat $L P L$ cDNAs. This glycine residue is highly conserved across species and within members of the lipase gene family (Fig. 3). The paralogous residue is also conserved in the human (29-31) and rat (32) hepatic lipase and the canine (33) pancreatic lipase genes.

Northern analysis. The human LPL transcript consists of two mRNA species of $\sim 3.3$ and $3.7 \mathrm{~kb}$ that arise from alternative sites of $3^{\prime}$ terminal polyadenylation $(4,18)$. Similarly, the cat demonstrates multiple transcripts with a primary transcript of $3.4 \mathrm{~kb}$ and in addition two other transcripts of $\sim 8$ and 1.6 $\mathrm{kb}$. Multiple mRNA transcripts have been seen in all other species except the rat, which has a single $3.6-\mathrm{kb}$ transcript $(25$, $34)$. The bovine cDNA detects a $1.7-\mathrm{kb}$ transcript in addition to a primary transcript of $3.6 \mathrm{~kb}(24)$. Northern analysis of a wide spectrum of tissues sampled from normal, heterozygous, and homozygous LPL-deficient cats reveals no differences in transcript size and levels of expression between genotypes

Table I. Features of Lipoprotein Lipase Deficiency in Humans and the Cat

\begin{tabular}{|c|c|c|}
\hline & Human & Cat \\
\hline Clinical Features & $\begin{array}{l}\text { Chylomicronemia } \\
\text { Cutaneous Xanthomata } \\
\text { Lipemia retinalis } \\
\text { Pancreatitis } \\
\text { Hepatosplenomegaly } \\
\text { Failure to thrive }\end{array}$ & $\begin{array}{l}\text { Chylomicronemia } \\
\text { Cutaneous Xanthomata } \\
\text { Lipemia retinalis } \\
\text { Failure to thrive } \\
\text { Pancreatitis? }\end{array}$ \\
\hline Inheritance & Autosomal recessive & Autosomal recessive \\
\hline Genetic defect & $>50$ different mutations in the LPL gene & G412R mutation in the LPL gene \\
\hline
\end{tabular}




\begin{tabular}{|c|c|c|c|c|c|c|c|c|c|c|}
\hline & & & & & & (409) & & & & \\
\hline Human LPL & Ile & Arg & Val & Lys & Ala & Gly & Glu & Thr & Gln & $\mathrm{L}$ \\
\hline Normal Cat LPL & * & $*$ & $*$ & * & $*$ & $*$ & * & * & * & \\
\hline Mouse LPL & * & * & $*$ & * & $*$ & $*$ & * & $*$ & * & \\
\hline Bovine LPL & * & $*$ & * & * & * & * & * & $*$ & * & \\
\hline Rat LPL & * & $*$ & $*$ & * & $*$ & $*$ & * & $*$ & * & \\
\hline Guinea Pig LPL & $*$ & * & * & * & $*$ & $*$ & * & $*$ & $*$ & \\
\hline Chicken LPL & Val & $*$ & $*$ & * & Ser & $*$ & * & $*$ & $*$ & \\
\hline Human HL & * & * & $*$ & $*$ & $*$ & $*$ & * & $*$ & $*$ & \\
\hline Rat HL & * & Trp & * & * & $*$ & $*$ & * & * & $*$ & \\
\hline Dog PL & * & Thr & $*$ & Gln & Lys & $*$ & $*$ & Glu & Lys & \\
\hline Affected Cat LPL & * & * & $*$ & * & $*$ & Arg & $*$ & * & $*$ & \\
\hline & & & & & & $(412)$ & & & & \\
\hline
\end{tabular}

Figure 3. Amino acid sequence comparison as predicted from the LPL cDNA sequences of seven species $(18,24-28)$, and two hepatic lipase (29-32) and one pancreatic lipase (34) gene family members. The residue that corresponds to 412 in the cat (Glycine) is conserved in all species and in hepatic lipase and pancreatic lipase genes, suggesting that this residue is important for the functioning of these lipases.
(Fig. 4). The most abundant feline transcript is seen in the heart, with lower levels of expression in other tissues including skeletal muscle, adipose, mammary gland, ovary, pancreas, brain, kidney, lymph node, and lung. LPL mRNA was not observed in bone marrow, liver, and frontal cortex. These studies reveal that this mutation does not induce any obvious changes at the transcriptional level.

Phenotypic and biochemical characterization of cats with the Gly412Arg mutation. These cats homozygous for the Gly412Arg mutations manifest with a phenotype similar to that seen in humans with LPL deficiency including lactescent plasma due to chylomicronemia, peripheral xanthomata, lipemia retinalis, and failure to thrive (Table I) (Fig. 5). Biochemical analysis has revealed that cats homozygous for the Gly412Arg mutation lack both detectable immunoreactive LPL mass and catalytic activity using the 502 antibody (Table II).

Similar to the mouse, the cat has most of its total cholesterol in the form of HDL (35). However the cat has distinct $\mathrm{HDL}_{2}$ and $\mathrm{HDL}_{3}$ subfractions similar to that of human (36) but not observed in the mouse. Lipoprotein analysis of affected cats revealed markedly elevated triglyceride levels when fed a low fat diet $(12 \%$ fat $)(P<0.05)$ (Table III). Heterozygous male cats also had significantly $(P<0.05)$ higher triglyceride values than normal cats. FPLC analysis of plasma lipoproteins of male homozygotes compared to normal siblings revealed an increase in VLDL triglyceride associated with a decrease in HDL cholesterol, consistent with a defect in LPL catalytic activity (Fig. 6). For cats of each genotype and sex, the total cholesterol to HDL-cholesterol ratio was measured and found to be elevated specifically in homozygotes for this mutation (Table III).

Cats homozygous for the Gly412Arg mutation demonstrate diminished growth rates and an increased rate of still-

Table II. LPL Mass and Activity According to Genotype in LPL-deficient Cats (Mean $\pm S D)$

\begin{tabular}{ccc}
\hline \multicolumn{1}{c}{ Genotype } & LPL Mass* & LPL Activity \\
\hline & $n g / m l$ & $m U / m l$ \\
LPL $-/-(n=5)$ & $7 \pm 10$ & 0 \\
LPL $+/-(n=10)$ & $62 \pm 18$ & $84 \pm 31$ \\
LPL $+/+(n=8)$ & $151 \pm 23$ & $272 \pm 70$
\end{tabular}

*As detected by monoclonal antibody $5 \mathrm{D} 2 ;{ }^{*} 1 \mathrm{nmol} / \mathrm{FFA} / \mathrm{min}=1 \mathrm{mU} / \mathrm{ml}$. born offspring. A cohort of male cats consisting of five normal, eight heterozygotes, and four cats homozygous for the mutation were weighed daily, with weights averaged for each genotype and plotted as a function of time (Fig. 7). Homozygous kittens have significantly reduced weights at birth $(P<0.01)$, at $20 \mathrm{wk}(P<0.001)$, and $36 \mathrm{wk}(P<0.0001)$ of age relative to both normal and heterozygous kittens, while consuming the same low fat diet.

In addition, kittens born to females homozygous for the gene defect have a significantly increased rate of stillbirth compared to offspring from matings of normal or Gly412Arg heterozygous females $(P<0.002)$ (Table IV). Normal $(L P L+/+)$ females mated with male Gly412Arg homozygotes resulted in no stillbirths among 16 offspring. In contrast, matings between
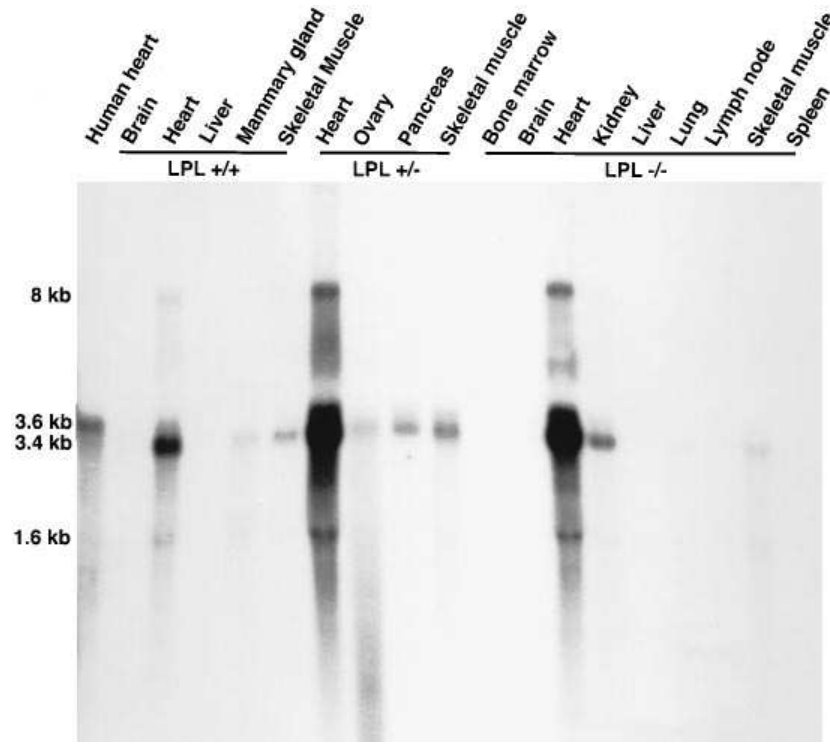

Figure 4. Northern analysis of total RNA from 12 different tissues from cats of all genotypes for the Gly412Arg mutation. The total RNA concentration in LPL $+/+$ heart was approximately half that of all other lanes as determined by hybridization with a $\beta$-Actin probe (data not shown). There is no alteration in transcript size or relative level of expression in cats of different genotypes. The highest level of expression occurs in the heart. LPL mRNA is also seen in skeletal muscle, mammary gland, ovary, pancreas, hind-brain, kidney, lymph node, and lung. The primary transcript is $3.4 \mathrm{~kb}$ with two other transcripts of $\sim 8$ and $1.6 \mathrm{~kb}$. 
a)

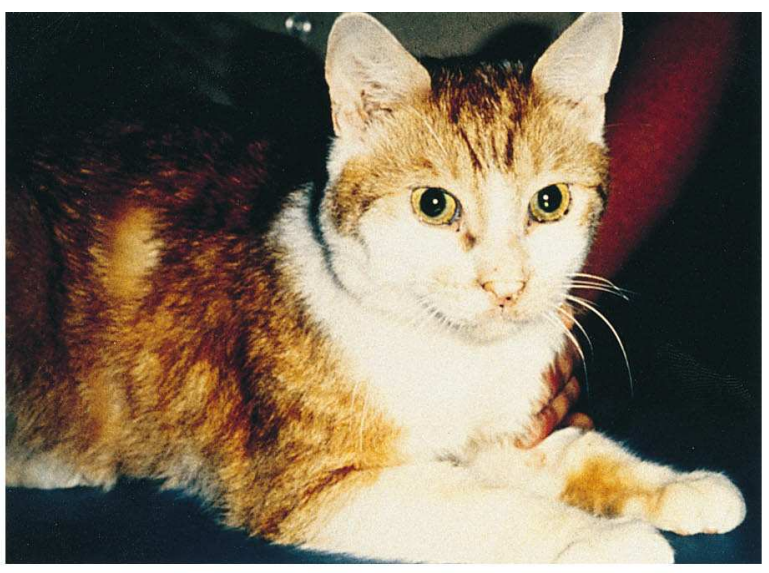

c)

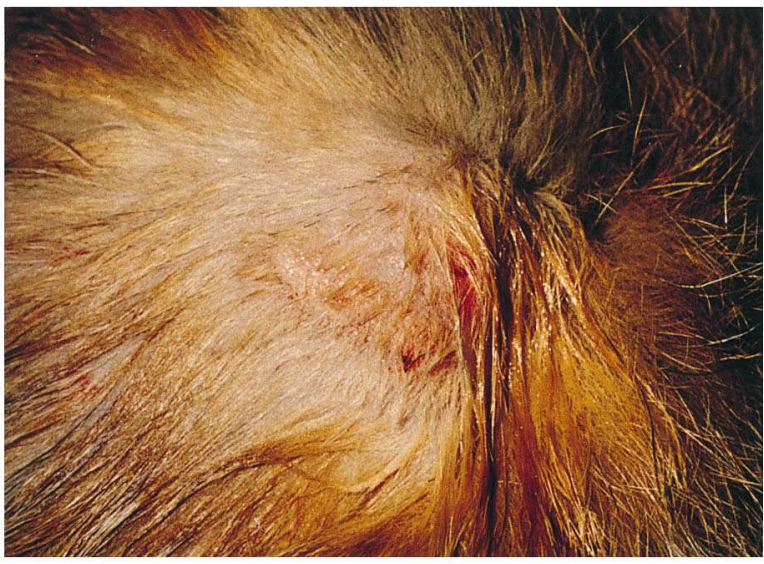

b)

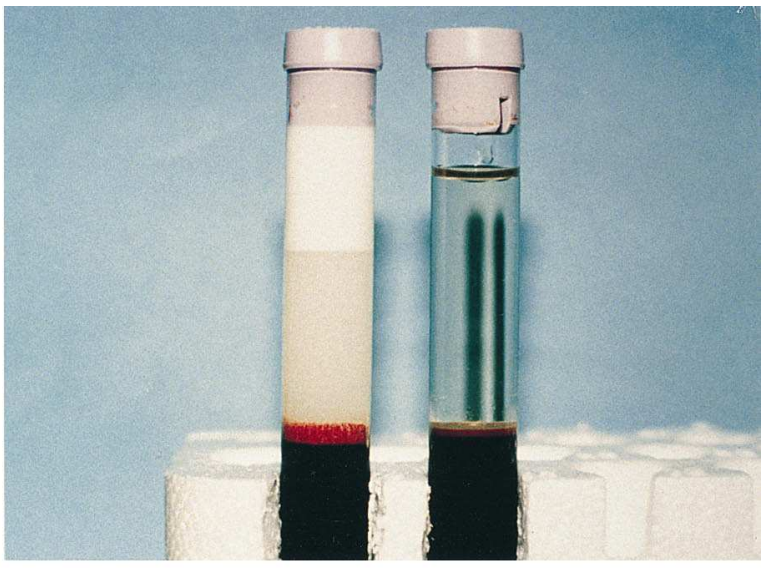

d)

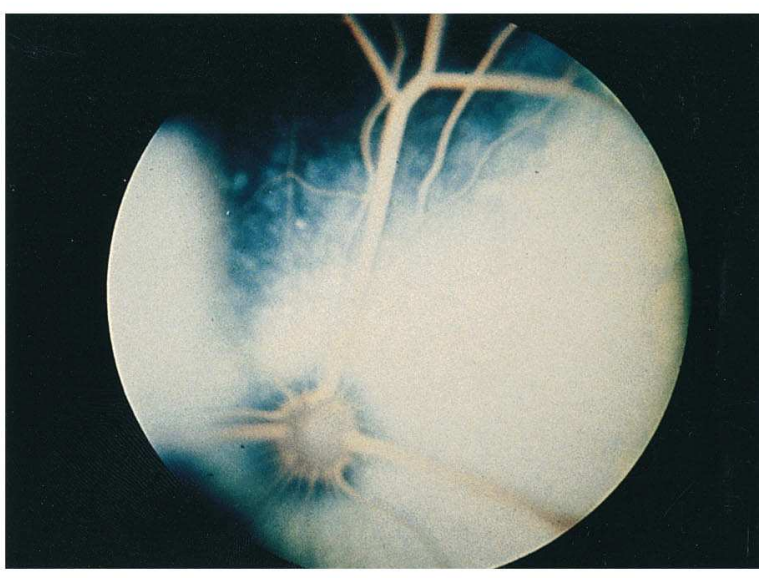

Figure 5. (a) A cat homozygous for the Gly412Arg mutation with no immediately obvious phenotypic abnormalities when fed a normal diet. (b) Overnight fasting plasma samples indicate obvious chylomicronemia in the LPL deficient homozygote cat (left) compared to normal (right). (c) A subcutaneous xanthoma on a LPL deficient cat, similar to that seen in affected humans. (d) Retinal examination reveals obvious lipemia retinalis in the affected cat.

homozygous LPL-deficient females and heterozygote males revealed 13/32 stillbirths. These findings suggest that the LPL genotype of the pregnant female is most likely the contributing factor to this increased stillbirth rate.

Functional assessment of Gly412Arg substitution in the feline LPL gene. The glycine in position 412 of the cat gene is equivalent to glycine at position 409 in the human gene (18).
Using site-directed mutagenesis this mutation was recreated in the human cDNA. In addition, using standard RT-PCR techniques, we isolated both a normal and affected cat $L P L$ cDNA. Expression studies after transfection of Cos-I cells, revealed that LPL catalytic activity was completely abolished due to this substitution using both the human and cat constructs (Table V).

Table III. Fasting Feline Lipid Values on a Low Fat Diet (12\%)

\begin{tabular}{|c|c|c|c|c|c|}
\hline & Triglycerides & Total cholesterol & HDL-cholesterol & LDL-cholesterol & TC/HDL-C ratio \\
\hline & mean & mean & mean & mean & \\
\hline \multicolumn{6}{|l|}{ Male } \\
\hline Homozygotes $(n=4)$ & $6.78 \pm 3.68 *$ & $4.37 \pm 3.16$ & $2.55 \pm 0.49$ & 0.00 & 1.71 \\
\hline Heterozygotes $(n=8)$ & $0.27 \pm 0.14^{\ddagger}$ & $4.41 \pm 1.46$ & $3.40 \pm 0.97$ & $0.65 \pm 0.37$ & 1.30 \\
\hline $\operatorname{Normal}(n=6)$ & $0.12 \pm 0.10$ & $3.33 \pm 0.53$ & $2.59 \pm 0.37$ & $0.75 \pm 0.35$ & 1.29 \\
\hline \multicolumn{6}{|l|}{ Female } \\
\hline Homozygotes $(n=3)$ & $5.87 \pm 2.58 *$ & $2.98 \pm 1.48$ & $2.12 \pm 0.47$ & 0.00 & 1.59 \\
\hline Heterozygotes $(n=4)$ & $0.26 \pm 0.13$ & $3.15 \pm 0.48$ & $2.68 \pm 0.46$ & $0.48 \pm 0.21$ & 1.18 \\
\hline $\operatorname{Normal}(n=3)$ & $0.24 \pm 0.17$ & $2.43 \pm 0.30$ & $2.00 \pm 0.31$ & $0.51 \pm 0.03$ & 1.22 \\
\hline
\end{tabular}

${ }^{*} P<0.05$ compared to normal and heterozygotes; ${ }^{\ddagger} P<0.05$ compared to normal. All other comparisons are not significant. Results are expressed as millimoles per liter. TC, total cholesterol. 

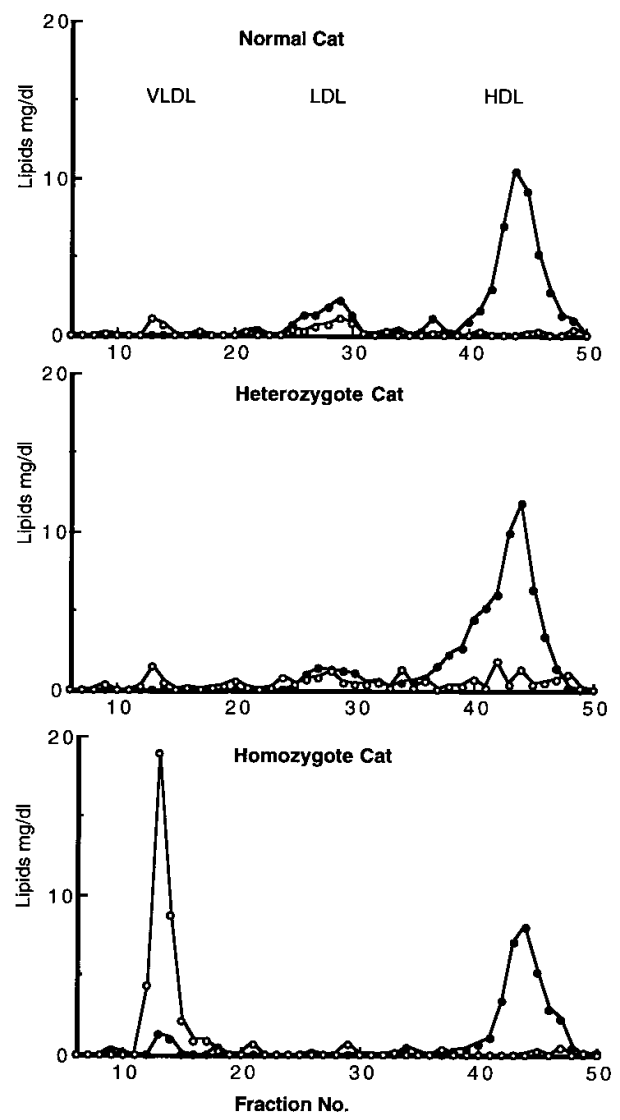
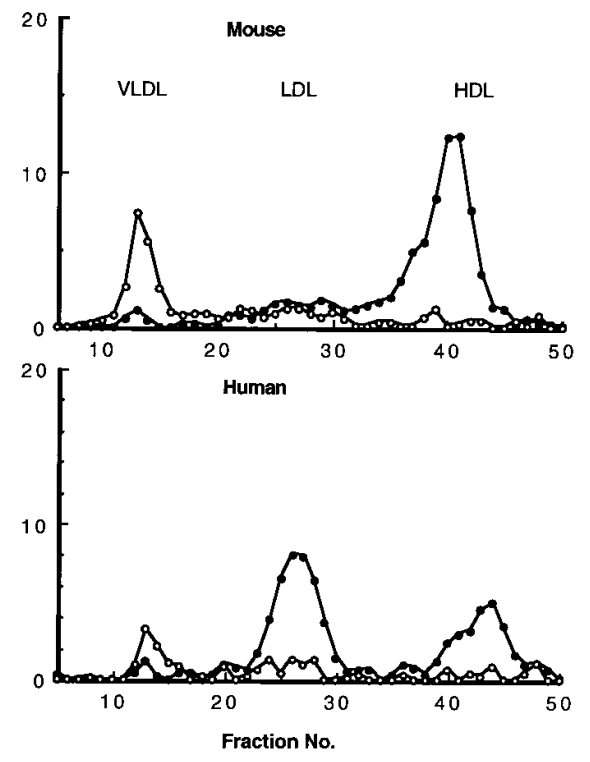

Figure 6. An FPLC profile from a normal, a heterozygote, and a homozygote cat for the Gly412Arg mutation. - - represents the amount of cholesterol per fraction $(\mathrm{mg} / \mathrm{ml})$, while the - $\mathrm{O}-$ notation represents the amount of triglyceride per fraction $(\mathrm{mg} / \mathrm{ml})$. Plasma samples were taken after an overnight fast and subjected to FPLC using two Superose 6 columns. Significant triglyceride peaks in the homozygote cat are evident. HDL cholesterol levels are reduced in the homozygote compared to normal. Comparison of the normal cat FPLC profile to that of the human and mouse indicates that the cat has a lipid profile similar to the mouse.
The development of a PCR-based mismatch primer approach allowed direct detection of the Gly412Arg mutation (Fig. 8). Analysis of this mutation in 50 members of this cat kindred revealed in all instances that those cats $(n=11)$ with chylomicronemia and complete LPL deficiency were homozygotes for the Gly412Arg mutation, while heterozygotes $(n=$ 23) had an intermediate biochemical phenotype (Fig. 9).

\section{Discussion}

Affected cats with chylomicronemia have a clinical phenotype similar to humans with LPL deficiency. Here we show that the affected phenotype in this cat colony is caused by a point mutation in amino acid residue 412 (Gly412Arg) in the $\mathrm{COOH}$ terminus of the cat $L P L$ gene. This residue corresponds to codon 409 in the human $L P L$ gene and is highly conserved in the $L P L$ genes of at least seven other species and two related lipase gene family members, hepatic lipase and pancreatic lipase (Fig. 3). Apart from sharing a similar clinical phenotype,

Table IV. Frequency of Stillbirths

\begin{tabular}{llcc}
\hline & \multicolumn{2}{c}{ Males } \\
\cline { 3 - 4 } & & Heterozygotes & Homozygotes \\
\hline \multirow{4}{*}{ Females } & Normal & $1 / 16(6 \%)$ & $0 / 16(0 \%)$ \\
& Heterozygotes & $5 / 35(14 \%)$ & $0 / 7(0 \%)$ \\
& Homozygotes* & $10 / 24(42 \%)$ & $3 / 8(37 \%)$
\end{tabular}

$* P<0.002$ compared to normal female cats. there is the highest degree of conservation of DNA sequence identity (90\%) and amino acid identity (94.5\%) between human and feline $L P L$ species compared to all other nonprimate $L P L$ species (14-28). Further assessment of the significance of this amino acid substitution by both site-directed in vitro mutagenesis, expression studies, and segregation analysis of this mutation with the affected phenotype confirms this Gly412Arg mutation as the cause of LPL deficiency in this cat colony.

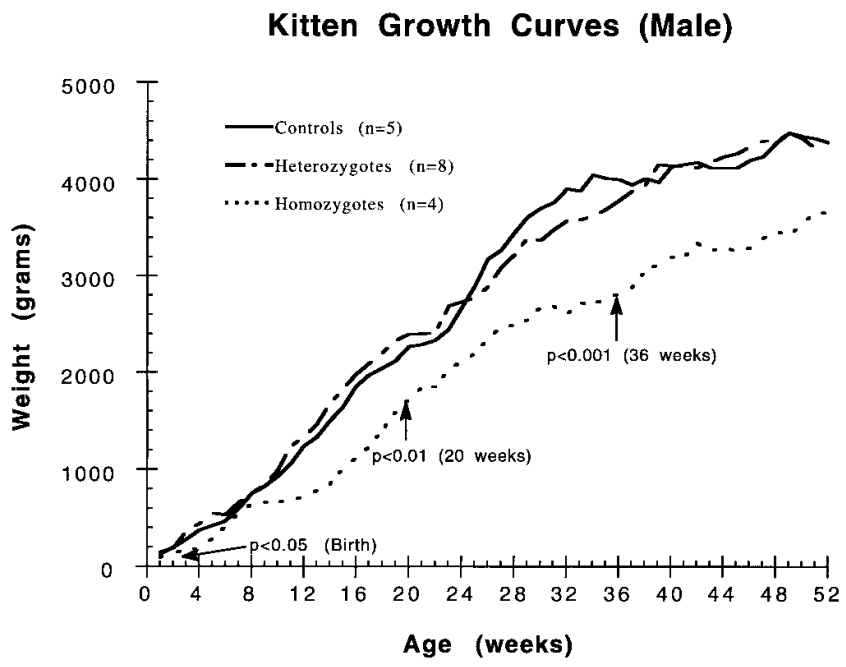

Figure 7. LPL-deficient kittens have reduced birth weights and maintain a reduced growth rate into adulthood. 
Table V. In Vitro Mutagenesis and Expression Studies

\begin{tabular}{lc}
\hline & LPL enzymatic activity \\
\hline & $m U / m l($ mean $\pm S D)$ \\
Normal Cat LPL cDNA $(n=5)$ & $39.73 \pm 6.4$ \\
Affected Cat LPL cDNA $($ Gly412Arg $)(n=5)$ & 0 \\
Normal Human LPL cDNA $(n=3)$ & $129.38 \pm 24.2$ \\
Gly409Arg Human LPL cDNA $(n=3)$ & 0 \\
\hline
\end{tabular}

LPL comprises two domains, with a larger $\mathrm{NH}_{2}$-terminal region containing the catalytic triad, active site, and loop residues $(1,5,37)$. The smaller $\mathrm{COOH}$-terminal domain is likely to be involved in lipid binding (38), interaction with heparin $(39,40)$, and the LDL-related receptor (41). Most mutations underlying human LPL deficiency have resided in exons 4,5 , and 6 , close to the residues in the catalytic triad $(1,7,42)$. A mutation at residue 410 of the human gene has also been shown to cause familial LPL deficiency (43). However, the mechanism whereby this Gly412Arg substitution causes LPL deficiency is not yet understood. This residue lies within a stretch of seven residues highly conserved in all $L P L$ species, as well as hepatic lipase. Furthermore, these specific residues are postulated to be involved in lipid binding and binding to LDL-related receptor (44). The absence of any immunoreactive LPL mass (using mAb 5D2) in homozygous cats also suggests that this mutation may significantly alter the conformation of the LPL protein resulting in rapid dissociation of active LPL dimeric protein into inactive monomers.

One intriguing observation is the higher frequency of stillbirths in offspring of female homozygotes which appears to be independent of the LPL genotype of the developing kitten but related to the genotype of the mother. LPL is crucial for the uptake and mobilization of energy in the form of free fatty acids which are a critical energy source for the developing fetus (45). In a pregnant cat with complete LPL deficiency, this
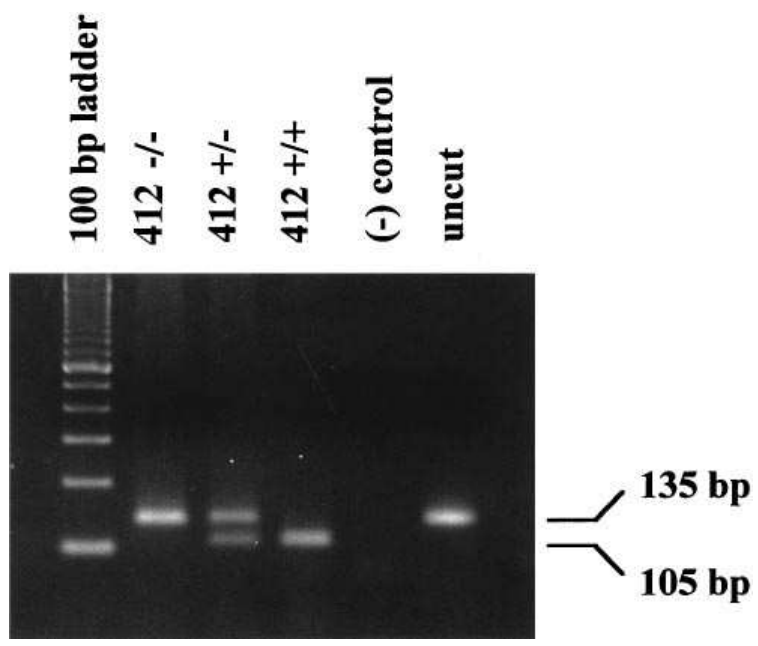

Figure 8. PCR mismatch analysis of the Gly412Arg mutation. After amplification of genomic DNA from cats of each genotype, the PCR product was digested with the restriction enzyme BstNI for $2 \mathrm{~h}$ at $50^{\circ} \mathrm{C}$ and resolved on a $3 \%$ agarose gel. Those alleles carrying this mutation are not digested with this enzyme and yield a $135 \mathrm{bp}$ band $(412-/-)$. The alleles that contain the normal sequence are digested by this enzyme and produce a band that runs at $105 \mathrm{bp}(412+/+)$.

function may be severely compromised and underlie the intrauterine mortality of the developing kittens. This hypothesis is supported by studies in guinea pigs (45) which revealed that in the last trimester, levels of free fatty acids, derived from maternal triglyceride-rich particles, are transported across the placenta at a greatly increased rate. The inability of the mother to mobilize fatty acids at this stage may be an important factor in the higher rate of stillbirths. There are no comparable reports of impaired reproductive fitness of humans with complete LPL deficiency. This may be due to alternative pathways for mobilizing free fatty acids or earlier miscarriages which have not been formally ascertained.

Homozygous kittens also grow at a significantly reduced

\section{LPL Deficient Cat Pedigree}

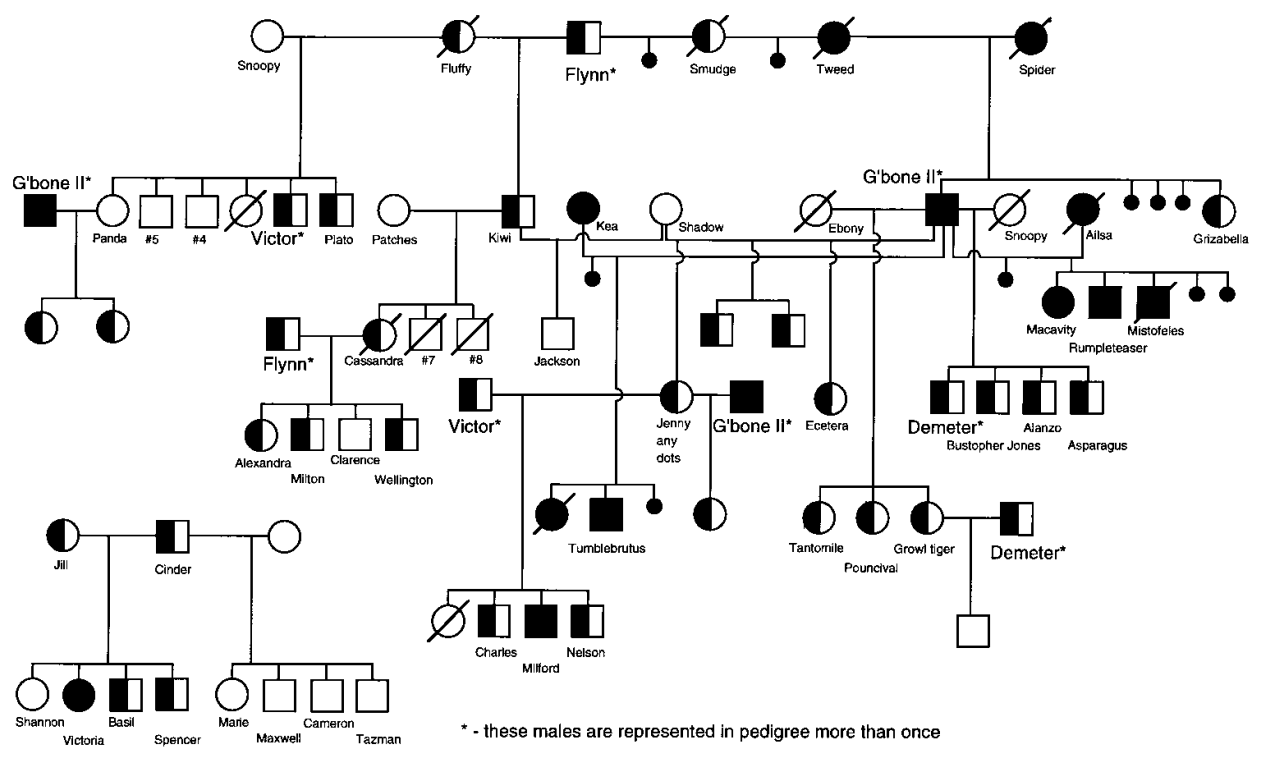

Figure 9. Pedigree of the cat colony. All cats homozygous for the Gly412Arg mutation have chylomicronemia and have no LPL activity (filled in boxes). Cats that are heterozygotes for this mutation (half filled) have an intermediate biochemical phenotype. 
rate from that of normal kittens and heterozygotes. It is possible that this may also be the result of decreased availability of energy derived from fatty acids for the growing kitten. Persistence of this finding into adulthood is marked by a profound generalized decrease in total body fat (data not shown), which in the case of a homozygous pregnant female may further exacerbate the difficulty of mobilizing fatty acids from adipose stores.

There have only been a few studies of the lipid transport system as well as the assessment of atherosclerosis in the domestic cat $(35,36,46,47)$. Clearly, for the elucidation of the function of lipases which may be involved in the metabolism of triglyceride rich lipoproteins and the metabolism of HDL subfractions, an animal model is needed in which the lipoprotein pattern and lipid transport system is close to that of humans. In this respect, it has been proposed that the cat may be an appropriate animal model because it is the only animal from many different laboratory and domestic animal species tested that has two separate HDL subfractions together with a distinct LDL fraction (36).

Ultracentrifugation reveals that the cat has two HDL bands that are similar to the average density boundaries of human $\mathrm{HDL}_{2}$ and $\mathrm{HDL}_{3}$, respectively. Furthermore, fasting cat VLDL and intermediate density lipoprotein has a similar apoprotein composition to human VLDL/intermediate density lipoprotein containing proteins such as apo B100, apo B48, apo $\mathrm{E}$, and apo $\mathrm{C}$. Both cat and human $\mathrm{HDL}_{2}$ contain apo $\mathrm{A} 1$ as the major lipoprotein. The cat, in contrast to the mouse which has approximately four to five times the amount of LPL in post-heparin plasma (48) as human, has levels of plasma LPL activity that are similar to that seen in the human (9).

Studies in transgenic mice suggest that variations in LPL activity are associated with altered lipid and lipoprotein levels which would predict an altered susceptibility to atherosclerosis (48). Furthermore, studies of patients heterozygous for mutations in the $L P L$ gene have revealed decreased levels of HDL-2 and Lp-A1 which may be associated with an increased risk for atherosclerosis (49). This is particularly pertinent, as some LPL mutations (e.g., Asp291Ser) may be seen in $\sim 2 \%$ of the general population (49). To date, however, no studies have been reported which examine the frequency of atherosclerosis due to either complete or partial LPL-deficiency.

The availability of a feline model of LPL deficiency resembling the human disorder and sharing some mechanisms of lipid transport offers a novel opportunity to assess the role of LPL in lipoprotein metabolism in a well characterized, experimental, in vivo system on a genetic background that is relatively homogeneous. In addition, the effects of this mutation on growth will allow further in vivo studies of the role of LPL in body fat accumulation. The availability of a gene-targeted mouse resulting in complete LPL deficiency would provide similar opportunities for studies of the heterozygote, but studies in the homozygote are not possible as death occurs within the first $2 \mathrm{~d}$ of life (50). Because the feline lipid transport system has significant similarities to the human and a clinical phenotype of LPL deficiency that closely parallels that in the human, the study of these LPL-deficient cats provides additional and highly complimentary information to the studies of the gene-targeted LPL deficient mice. Thus, as the Watanabe Heritable Hyperlipidemic (WHHL) rabbit serves as a paradigm for assessing LDL receptor function and therapeutic strategies, the LPL-deficient cat could represent an important in vivo model for evaluating the relationship between elevation of triglyceride-rich lipoproteins, atherogenic risk, and potential efficacy of therapeutic agents including gene therapy.

\section{Acknowledgments}

We would like to thank Quinton Rogers for his helpful discussions, advice on feline nutrition, and animal husbandry. We also thank Dr. J. Brunzell for the generous gift of the LPL antibodies. We acknowledge Zabeen Ladha, Karen Holzman, and Tammy Dauphinee for their invaluable support in the management and care of the animals used in these studies, Li Miao for her technical assistance, and Natalie Spence and Suzanne Clee for their assistance with manuscript preparation.

This work is supported by grants from Medical Research Council (MRC) (Canada). D.G. Ginzinger and G. Liu are supported by the Heart and Stroke Foundation of British Columbia and Yukon. M.E.S. Lewis is an MRC postdoctoral fellow (Canada). M.R. Hayden is an established investigator of the British Columbia Children's Hospital.

\section{References}

1. Brunzell, J.D. 1995. Familial lipoprotein lipase deficiency and other causes of the chylomicronemia syndrome. In Metabolic Basis of Inherited Disease. 7th Ed. C.R. Scriver, A.L. Beaudet, W.S. Sly, and D. Valle, editors. McGraw-Hill Book Co., New York. 1913-1932.

2. Patsch, J.R., A.M. Gotto, Jr., T. Olivecrona, and S. Eisenberg. 1978. Formation of high density lipoprotein ${ }_{2}$-like particles during lipolysis of very low density lipoproteins in vitro. Proc. Natl. Acad. Sci. USA. 75:4519-4523.

3. Patsch, J.R., S. Prasad, A.M. Gotto, Jr., and W. Patsch. 1987. High density lipoprotein ${ }_{2}$ : relationship of the plasma levels of this lipoprotein species to its composition, to the magnitude of postprandial lipemia, and to the activities of lipoprotein lipase and hepatic lipase. J. Clin. Invest. 80:341-347.

4. Braun, E.A., and D.L. Severson. 1992. Regulation of the synthesis, processing and translocation of lipoprotein lipase. Biochem. J. 287:337-347.

5. Olivecrona, T., and G. Bengtsson-Olivecrona. 1993. Lipoprotein lipase and hepatic lipase. Curr. Opin. Lipidol. 4:187-196.

6. Persson, B.G., G. Bengtsson-Olivecrona, S. Enerback, T. Olivecrona, and H. Jornvall. 1989. Structural features of lipoprotein lipase: lipase family relationships, binding interactions, non-equivalence of lipase cofactors, vitellogenin similarities and functional subdivision of lipoprotein lipase. Eur. J. Biochem. 179:39-45.

7. Santamarina-Foho, S., and H.B. Brewer, Jr. 1991. The familial hyperchylomicronemia syndrome. New insights into underlying genetic defects. JAMA (J. Am. Med. Assoc.). 265:904-908.

8. Jones, B.R., W.S. Hancock, and C.H. Campbell. 1983. Occurrence of idiopathic, familial hyperchylomicronemia in a cat. Vet. Rec. 112:543-547.

9. Peritz, L.N., J.D. Brunzell, P.H. Pritchard, B.R Jones, and M.R. Hayden. 1990. Characterization of a lipoprotein lipase Class III type defect in hypertriglyceridemic cats. Clin. Invest. Med. 13:259-263.

10. Hara, I., and M. Okazaki. 1986. High performance liquid chromatography of serum lipoproteins. Methods Enzymol. 129:57-81.

11. Peterson, J., W.Y. Fujimoto, and J.D. Brunzell. 1992. Human lipoprotein lipase: relationship of activity, heparin affinity and conformation as studied with monoclonal antibodies. J. Lipid Res. 33:1165-1170.

12. Iverius, P.H., and J.D. Brunzell. 1985. Human adipose tissue lipoprotein lipase: changes with feeding and relation to postheparin plasma enzyme. Am.J. Physiol. 249:E107-E114.

13. Babirak, S.P., P.H. Iverius, W.Y. Fujimoto, and J.D. Brunzell. 1989. The detection and characterization of the heterozygous state for lipoprotein lipase deficiency. Arteriosclerosis. 9:326-334.

14. Chomczynski, P., and N. Sacchi. 1987. Single-step method of RNA isolation by acid guanidium thiocyanate-phenol-chloroform extraction. Anal. Biochem. 162:156-159.

15. Feinberg, A.P., and B. Vogelstein. 1983. A technique for radiolabeling DNA restriction endonuclease fragments to high specific activity. Anal. Biochem. 132:6-13.

16. Sambrook, J., E.F. Fritsch, and T. Maniatis. 1989. Molecular Cloning. A Laboratory Manual. Cold Spring Harbor Laboratory, Cold Spring Harbor, NY. 17. Sanger, F., S. Nicklen, and A.R. Coulson. 1977. DNA sequencing with chain-terminating inhibitors. Proc. Natl. Acad. Sci. USA. 74:5463-5467.

18. Wion, K.L., T.G. Kirchgessner, A.L. Lusis, M.C. Schotz, and R.M Lawn. 1987. Human lipoprotein lipase complimentary DNA sequence. Science (Wash. DC). 235:1638-1641.

19. Frohmann, M.A. 1990. Rapid amplification of cDNA ends. In PCR Pro- 
tocols. M.A. Innis, D.H. Gelfand, J.J. Sninsky, and T.J. White, editors. Academic Press Inc., San Diego, CA. 28-38.

20. Zechner, R., T.C. Newman, E. Steiner, and J.L. Breslow. 1991. The structure of the mouse lipoprotein lipase gene: a B1 repetitive element is inserted into the 3' untranslated region of the mRNA. Genomics. 11:62-76.

21. Zoller, S., and M. Smith, 1987. Oligonucleotide-directed mutagenesis: a simple method using two oligonucleotide primers and a single stranded DNA template. Methods Enzymol. 154:329-350.

22. Henderson, H.E., Y. Ma, M.F. Hassan, M.V. Monsalve, A.D. Marais, F. Winkler, K. Gubernator, J. Peterson, J.D. Brunzell, and M.R. Hayden. 1991. Amino acid substitution (Ile194Thr) in exon 5 of the lipoprotein lipase gene causes lipoprotein lipase deficiency in three unrelated probands. J. Clin. Invest. 87:2005-2011.

23. Beverley, S.M. Enzymatic amplification of RNA by PCR. 1991. In Current Protocols in Molecular Biology. F.M. Ausubel, R. Brent, R.E. Kingston, D.D. Moore, J.G. Seidman, J.A. Smith, and K. Struhl, editors. Wiley Interscience. Boston, MA. Suppl. 17:15.4.4-15.4.6.

24. Senda, M., K. Oka, W.V. Brown, P.K. Oasba, and Y. Furuichi. 1987. Molecular cloning and sequence of a cDNA coding for bovine lipoprotein lipase. Proc. Natl. Acad. Sci. USA. 84:4369-4373.

25. Kirchgessner, T.G., K.L. Svenson, A.L. Lusis, and M.C. Schotz. 1987. The sequence of cDNA encoding lipoprotein lipase; a member of a lipase gene family. J. Biol. Chem. 262:8463-8466.

26. Brault, D., L. Noe, J. Etienne, J. Hamelin, A. Raisonnier, A. Souli, J.C. Chuat, I. Dugail, A. Quignard-Boulange, M. Lavau, et al. 1992. Sequence of rat lipoprotein lipase-encoding cDNA. Gene (Amst.). 121:237-246.

27. Enerback, S., H. Semb, G. Bengtsson-Olivecrona, P. Carlsson, M.L. Hermansson, T. Olivecrona, and G. Bjursell. 1987. Molecular cloning and sequence analysis of cDNA encoding lipoprotein lipase of guinea pig. Gene (Amst.). 58:1-12.

28. Cooper, D.A., S.C. Lu, R. Viswanath, R.N. Freiman, and A. Bensadoun. 1992. The structure and complete nucleotide sequence of the avian lipoprotein lipase gene. Biochim. Biophys. Acta. 1129:166-171.

29. Datta, S., C.C. Luo, W.H. Li., P. VanTuinen, D.H. Ledbetter, M.A. Brown, S.H. Chen, S.W. Liu, and L. Chan. 1988. Human hepatic lipase. Cloned cDNA sequence, restriction fragment length polymorphisms, chromosomal localization, and evolutionary relationships with lipoprotein lipase and pancreatic lipase. J. Biol. Chem. 263:1107-1110.

30. Stahnke, G., R. Sprengel, J. Augustin, and H. Will. 1987. Human hepatic triglyceride lipase: cDNA cloning, amino acid sequence and expression in a cultured cell line. Differentiation. 35:45-52.

31. Cai, S.J., D.M. Wong, S.H. Chen, and L. Chan. 1989. Structure of the human hepatic triglyceride lipase gene. Biochemistry. 28:8966-8971.

32. Komaromy, M.C., and M.C. Schotz. 1987. Cloning of rat hepatic lipase cDNA: evidence for a lipase gene family. Proc. Natl. Acad. Sci. USA. 84:15261530.

33. Mickel, F.S., F. Weidenbach, B. Swarovsky, K.S. LaForge, and G.A. Scheele. 1989. Structure of the canine pancreatic lipase gene. J. Biol. Chem. 264:12895-12901.

34. Semenkovich, C.F., S.-H. Chen, M. Wims, C.-C. Luo, W.-H. Li, and L. Chan. 1989. Lipoprotein lipase and hepatic lipase mRNA tissue specific expression, developmental regulation and evolution. J. Lipid Res. 30:423-431.

35. Chapman, M.J. 1980. Animal lipoproteins: chemistry, structure, and comparative aspects. J. Lipid Res. 21:789-853.

36. Demacker, P.N., P.J. van Heijst, H.L. Hak-lemmers, and A.F. Stalan- hoef. 1987. A study of the lipid transport system in the cat, Felix domesticus. Atherosclerosis. 66:113-123.

37. Henderson, H.E., Y. Ma, M.S. Liu, I. Clark-lewis, D.L. Meader, J.J.P. Kastelein, J.D. Brunzell, and M.R. Hayden. 1993. Structure-function relationships of lipoprotein lipase: mutation analysis and mutagenesis of the loop region. J. Lipid Res. 34:1593-1602.

38. Chappell, D.A., I. Inoue, G.L. Fry, M.W. Pladet, S.L. Bowen, P.H. Iverius, J.M. Lalouel, and D.K. Strickland. 1994. Cellular catabolism of normal very low density lipoproteins via the low density lipoprotein receptor-related protein/a2-macroglobulin receptor is induced by the C-terminal domain of lipoprotein lipase. J. Biol. Chem. 269:18001-18006.

39. Ma, Y., H.E. Henderson, M.S. Liu, H. Zhang, I.J. Forsythe, I. ClarkeLewis, M.R. Hayden, and J.D. Brunzell. 1994. Mutagenesis in four candidate heparin binding regions (residues 279-282, 291-304, 390-393 and 439-438) and identification of residues affecting heparin binding of human lipoprotein lipase. J. Lipid Res. 35:2049-2059.

40. Hata, A., D.N. Ridinger, S. Sutherland, S. Emi, S. Zhang, R.L. Myers, K. Ren, T. Cheng, I. Inoue, D.E. Wilson, et al. 1993. Binding of lipoprotein lipase to heparin. Identification of five critical residues in two distinct segments of the amino-terminal domain. J. Biol. Chem. 268:8447-8457.

41. Beisiegel, U., W. Weber, and G. Bengtsson-Olivecrona. 1991. Lipoprotein lipase enhances the binding of chylomicrons to low density lipoprotein receptor-related protein. Proc. Natl. Acad. Sci. USA. 88:8342-8346.

42. Hayden, M.R., and H. E. Henderson. 1995. The molecular biology and genetics of human lipoprotein lipase. In Lipoproteins in Health and Disease. D.J. Betterridge, D.R. Illingworth, and J. Shepard, editors. Edward Arnold Publishers, Kent, England. In press.

43. Previato, L., O. Guardamagna, K.A. Dugi, R. Ronan, G.D. Talley, S. Santmarina-Fojo, and H.B. Brewer, Jr. 1994. A novel missense mutation in the C-terminal domain of lipoprotein lipase (Glu410Val) leads to enzyme inactivation and familial chylomicronemia. J. Lipid. Res. 35:1552-1560.

44. Krapp, A., H. Zhang, D.G. Ginzinger, M.S. Liu, A. Lindberg, G. Olivecrona, M.R. Hayden, and U. Beisiegel. 1995. Use of in vitro mutagenesis to define residues in lipoprotein lipase involved in mediation of lipoprotein uptake into cells. J. Lipid Res. 36:2362-2373.

45. Thomas, C.R., and C. Lowy. 1983. Placental transfer of free fatty acids: factors affecting transfer across the guinea-pig placenta. J. Dev. Physiol. 5:323332

46. Demacker, P.N.M., A.G.M. Hijmans, A.F.H. Stalenhoef, and A. van't Laar. 1988. Studies of the function of hepatic lipase in the cat after immunological blockade of the enzyme in vivo. Atherosclerosis. 69:173-183.

47. Manning, P.J., and T.B. Clarkson 1970. Diet-induced atherosclerosis of the cat. Arch. Pathol. 89:271-278.

48. Liu, M.S., F.R. Jurik, R.C. Leboeuf, H. Henderson, L.W. Castellani, A.J. Lusis, Y. Ma, I.J. Forsythe, H. Zhang, E. Kirk, et al. 1994. Alteration of lipid profiles in plasma of transgenic mice expressing human lipoprotein lipase. J. Biol. Chem. 269:11417-11424.

49. Reymer, P.W.A., E. Gagne, B.E. Groenmeyer, H. Zhang, I. Forsyth, H. Jansen, J.C. Seidell, D. Kromhout, K.E. Lie, J.Kastelein, and M.R. Hayden. 1995. A lipoprotein lipase mutation (Asn291Ser) is associated with reduced HDL cholesterol levels in premature atherosclerosis. Nat. Gen. 10:28-33.

50. Coleman, T., R.L. Seip, J.M. Gimbel, D. Lee, N. Maeda, and C.F. Semenkovich. 1995. COOH-terminal disruption of lipoprotein lipase in mice is lethal in homozygotes, but heterozygotes have elevated triglycerides and impaired enzyme activity. J. Biol. Chem. 270:12518-12525. 